\title{
MIMO Beamforming Network Having Polarization Diversity
}

\author{
Kadir M.F. A., Suaidi M.K. and Aziz M. Z. A. \\ Universiti Teknikal Malaysia Melaka (UTeM) \\ Malaysia
}

\section{Introduction}

The technology of mobile communication and wireless local network (WLAN) are expending at a fast rate which is to assure that the end users reach a maximum data transfer and a get a better of quality service. The MIMO system is introduced to improve the communication system without having an additional transmit power or larger bandwidth, this because the MIMO system can utilize the multipath propagation.

In [Agilent, 2008], there are three categories of MIMO system. The first system is spatial diversity which can be obtain by spaced the antenna in a dense of multipath scattering environment. The second category is spatial multiplexing where an independent data is transmitted over different antennas. Third category is beamforming network. Generally the MIMO system can be divided into two parts, which the first part is the digital signal processing (DSP) and representing as Part $\mathbf{A}$ in Fig. 1. The second part is radio frequency (RF) device and representing as Part B in Fig. 1. (Jensen \& Wallace, 2004).

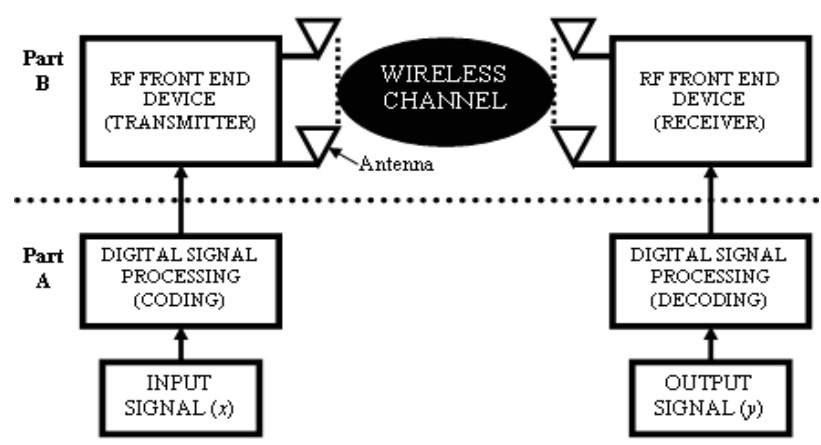

Fig. 1. Block diagram of MIMO systems

This paper is more focused to the RF section and antenna, the beamforming technique is used to act as MIMO system. The term beamforming related to the device in which energy radiated by an antenna that focused is focused along a specific direction in space (Mariadoss etc. al. 2005). So, there are several types of beamforming such as Blass matrix, Nolen matrix and Butler matrix (Desmond, 2001; Ahmad \& Seman, 2005). The Butler matrix is used in this project because it simple circuit and easy to be fabricated (Mariadoss etc. al. 2005). 


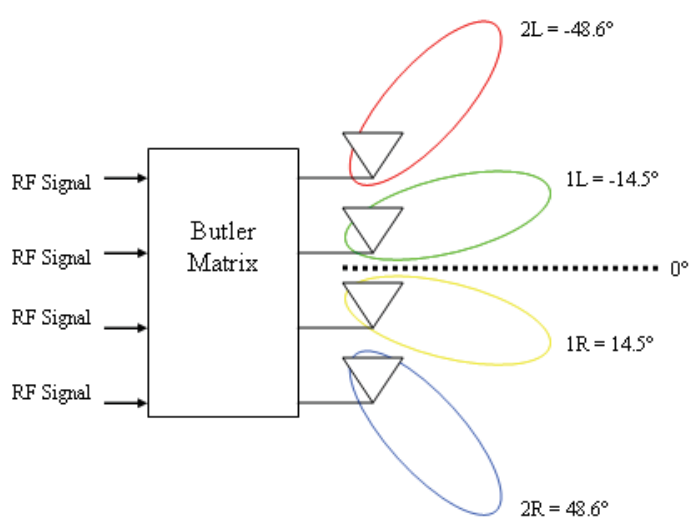

Fig. 2. An example of Butler matrix

Moreover, diversity technique was introduced in this measurement setup. The diversity is used to reduce the fading issues and multipath problems (Duman \& Ghrayeb, 2007). By implementing diversity, the received power can be increased significantly, thus increasing the capacity of the system. Polarization diversity, angle diversity and pattern diversity are among the examples of diversity technique.

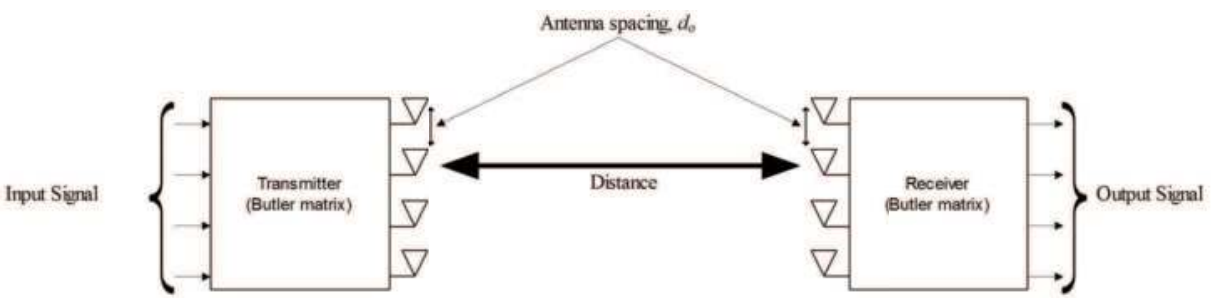

Fig. 3. The Concept of RF MIMO Front End Systems Measurement

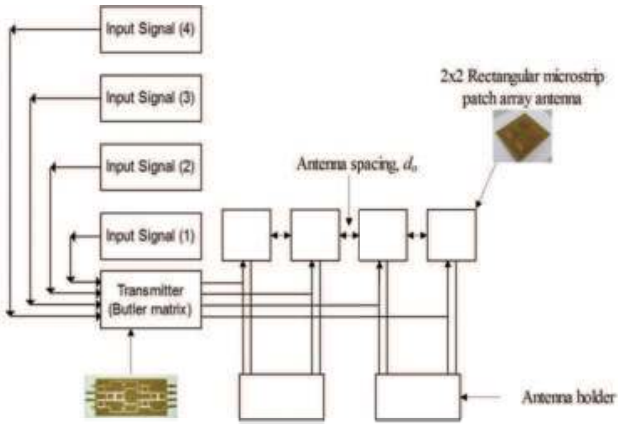

(a) Transmitter Setup

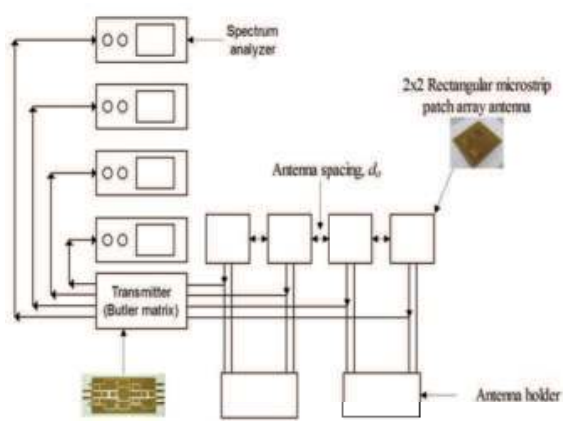

(b) Receiver Setup

Fig. 4. The Measurement Setup at (a) Transmitter (b) Receiver 


\section{MIMO channel matrix}

Each of antennas in MIMO systems has its own vector. The transmit antenna vector is represented as $x$ and the receive antenna is represented as $y$ vector. The MIMO channel input-output relationship can be expressed as:

$$
y=H x+\eta
$$

where the $\eta$ is the noise and $H$ is the MIMO channel matrix. The MIMO channel matrix size is depending on the number of transmit and receive antennas. The channel matrix size can be express as below:

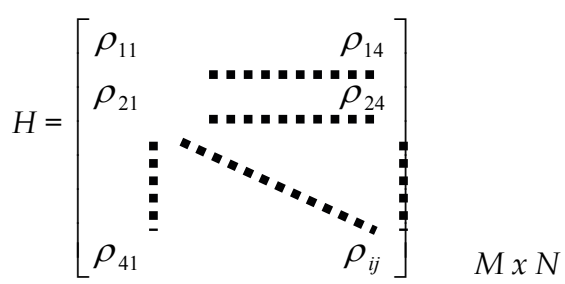

where $M$ was the number of transmit antenna and $N$ was the number of receive antenna. The $\rho_{i j}$ was represented as the correlation between transmit power and receive power where $\mathrm{i}^{\text {th }}$ was the input port and $\mathrm{j}^{\text {th }}$ was the output port signals. The $\rho_{i j}$ components were direct depended on the physical characteristics of the propagation environment and also the structure of the antenna array (Kermoal et al., 2000).

Correlation coefficient was a statistic method to measure the correlation between two variables. The correlation coefficient can be calculated as:

$$
\rho_{y x}=\frac{\operatorname{cov}_{y x}}{\sigma_{y y} \sigma_{x x}}
$$

The channel matrix, $H$ will be analyzed for each type of antenna configuration which can be referred in Appendix. The eigenvalues can be calculated to estimate the receiving power for each eigen paths. The eigenvalues were calculated using eigen value decomposition (EVD) technique. The calculated eigenvalues were related with the MIMO average channel capacity by using the equation below (Hirayama etc. al. 2007):

$$
C_{\text {ave }}=\left[\sum_{j=1}^{N} \log _{2}\left(1+\lambda_{j} S N R / N\right)\right]
$$

where $N$ was the number of transmit because there was no setting channel state information (CSI) at transmitter. $\lambda_{j}$ was the eigenvalues from the matrix, $H$ while the noise power of $76 \mathrm{dBm}$ was obtain from measurement. 


\section{Results and discussion}

\subsection{Antenna separation comparison}

Fig. 5. shows the average channel capacity for configuration A and B. The distance for this measurement is set for 12 meters. Its shows that the average channel capacity for antenna separation $12 \mathrm{~cm}$ are higher for both configurations. The average channel capacity difference for antenna spacing between $12 \mathrm{~cm}$ and $6 \mathrm{~cm}$ for configuration $\mathrm{A}$ is $2.2848 \mathrm{bps} / \mathrm{Hz}$ and configuration $\mathrm{B}$ is $2.473 \mathrm{bps} / \mathrm{Hz}$. For the entire antenna configuration can be referred to Appendix.

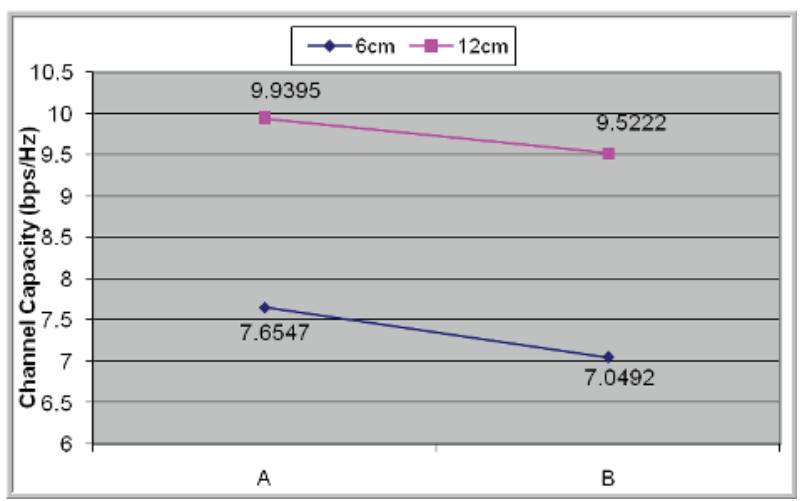

Fig. 5. Average Channel Capacity for Normal Configuration

In Fig. 6 (a)., the configuration E shows a higher average channel capacity is $9.193 \mathrm{bps} / \mathrm{Hz}$ with antenna separation is $12 \mathrm{~cm}$ and it is higher form others configuration. Fig. 6 (b). shows an average channel capacity for polarization diversity applied to the receiver side. Two configuration show high value which is indicated at configuration $G$ and configuration I with antenna separation $12 \mathrm{~cm}$.

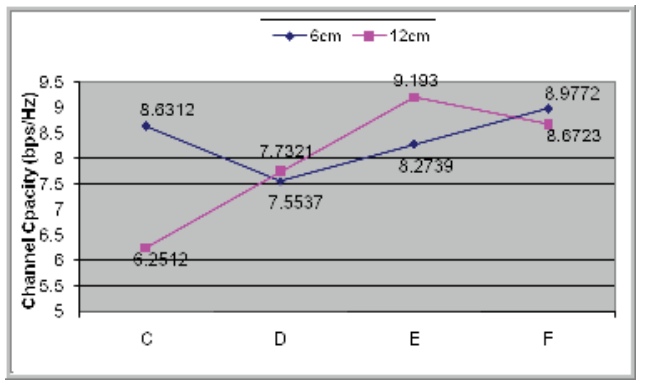

(a)

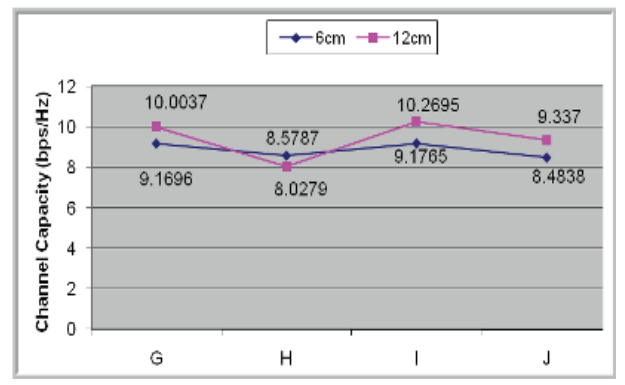

(b)

Fig. 6. (a) Average Channel Capacity for Polarization Diversity at Transmitter Fig. 6 (b). Average Channel Capacity for Polarization Diversity at Receiver 
Fig. 7. shows the average channel capacity for both sides polarization diversity. The higher values are indicated at configuration $\mathrm{K}, \mathrm{L}$ and $\mathrm{M}$. For $\mathrm{L}$ an $\mathrm{M}$ the antenna separation is 12 $\mathrm{cm}$, meanwhile the configuration $\mathrm{K}$ antenna separation is $6 \mathrm{~cm}$.

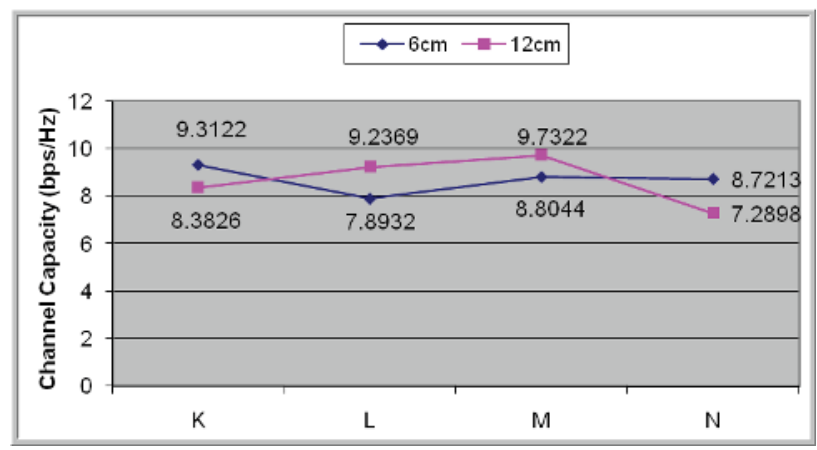

Fig. 7. Average Channel Capacity for Both Sides Polarization Diversity

\section{Conclusion}

As the conclusion, if the antenna spacing is double, the average channel capacity is increased. When polarization diversity is applied to the system, its show that average channel capacity is better than the normal configuration.

\section{References}

Agilent (2008). MIMO Channel Modelling and Emulation Test Challenges, Application Note, Agilent, pp. 1-60, Agilent Technologies, Inc, 5989-8973EN, USA

Ahmad, S.R. \& Seman, F.C. (2005). 4-port Butler matrix for Switched Multibeam Antenna Array, Proceedings of Asia-Pacific Conference on Applied Electromagnetics, 0-7803-94313, Dec. 2005

Duman, T.M \& Gharayeb, A. (2004). Coding for MIMO Communication Systems, Wiley, 978-0470-02809-4, England

Hirayama, H.; Hayashi, A. \& Kikuma, N.; Sakakibara. K. (2007). An Experimental Consideration On Spatial Correlation And Minimum Eigenvalue For MIMO Systems Using Polarization, Proceedings of The Second European Conference On Antennas and Propagation, pp. 1-5, 978-0-86341-842-6, Edinburgh, Nov. 2007

Jensen, M.A.; \& Wallace, J.W. (2004). A Review of Antennas and Propagation for MIMO Wireless Communication, IEEE Transaction on Antenna And Propagation, Vol. 52, No. 11, November 2004 pp. 0018-926X, Nov. 2004

Kermoal, J.P.; Schumacher, L. \& Pedersen, P.E. (2000). Experimental Investigation of Correlation Properties of MIMO Radio Channel for Indoor Picocell Scenarios, Proceeding of IEEE Vehicular Technology Conference, pp. 14-21, 0-7803-6507-0, Boston, MA, Sept. 2000, IEEE 
Mariadoss, P.Q; Rahim, M.K.A. \& Aziz, M.Z.A.A. (2005). Design and Implementation of A Compact Butler Matrix using Mitered Bends, Proceeding of APMC 2005, 0-7803-9433X, Dec. 2005 


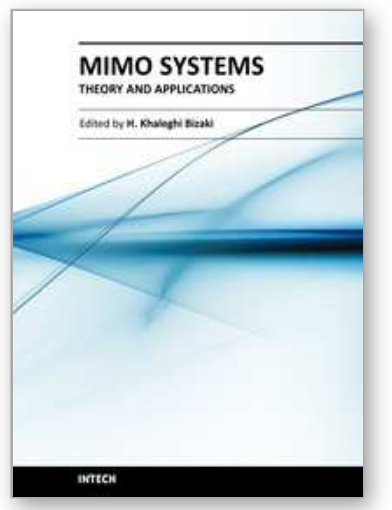

\author{
MIMO Systems, Theory and Applications \\ Edited by Dr. Hossein Khaleghi Bizaki
}

ISBN 978-953-307-245-6

Hard cover, 488 pages

Publisher InTech

Published online 04, April, 2011

Published in print edition April, 2011

In recent years, it was realized that the MIMO communication systems seems to be inevitable in accelerated evolution of high data rates applications due to their potential to dramatically increase the spectral efficiency and simultaneously sending individual information to the corresponding users in wireless systems. This book, intends to provide highlights of the current research topics in the field of MIMO system, to offer a snapshot of the recent advances and major issues faced today by the researchers in the MIMO related areas. The book is written by specialists working in universities and research centers all over the world to cover the fundamental principles and main advanced topics on high data rates wireless communications systems over MIMO channels. Moreover, the book has the advantage of providing a collection of applications that are completely independent and self-contained; thus, the interested reader can choose any chapter and skip to another without losing continuity.

\title{
How to reference
}

In order to correctly reference this scholarly work, feel free to copy and paste the following:

Kadir M.F. A., Suaidi M.K. and Aziz M. Z. A. (2011). MIMO Beamforming Network Having Polarization Diversity, MIMO Systems, Theory and Applications, Dr. Hossein Khaleghi Bizaki (Ed.), ISBN: 978-953-307245-6, InTech, Available from: http://www.intechopen.com/books/mimo-systems-theory-andapplications/mimo-beamforming-network-having-polarization-diversity

\section{INTECH}

open science | open minds

\section{InTech Europe}

University Campus STeP Ri

Slavka Krautzeka 83/A

51000 Rijeka, Croatia

Phone: +385 (51) 770447

Fax: +385 (51) 686166

www.intechopen.com

\section{InTech China}

Unit 405, Office Block, Hotel Equatorial Shanghai

No.65, Yan An Road (West), Shanghai, 200040, China 中国上海市延安西路65号上海国际贵都大饭店办公楼 405 单元

Phone: +86-21-62489820

Fax: $+86-21-62489821$ 
(C) 2011 The Author(s). Licensee IntechOpen. This chapter is distributed under the terms of the Creative Commons Attribution-NonCommercialShareAlike-3.0 License, which permits use, distribution and reproduction for non-commercial purposes, provided the original is properly cited and derivative works building on this content are distributed under the same license. 